\title{
How dictogloss can facilitate collocation learning in ELT
}

\author{
Per Snoder and Barry Lee Reynolds ${ }^{\circ}$
}

\section{Introduction}

This instructional intervention investigated the potential for the text reconstruction task dictogloss to facilitate the learning of English verb-noun collocations, for example 'carry a risk'. Research has shown that learners have difficulties in using such collocations, but few useful instructional techniques are on offer. Participants in the study were $G_{4} L_{1}$ Swedish adolescent learners of English. The effectiveness of two modified versions of the dictogloss was compared in a within-subjects design. This implied that participants in pairs co-reconstructed two texts containing target collocations, where each co-reconstruction was preceded by a specific priming activity to induce learners to process collocations as intact wholes. Results showed that having learners elaborate on the meaning of collocations in a pre-task activity outperformed a form-oriented pre-task activity on all measures, notably for productive knowledge on delayed post-tests. The findings are discussed in relation to previous research and their implications for ELT.

When English L2 learners speak or write, they often notice that combining words the way native speakers do is a challenge. For example, learners whose LI is Swedish or French easily understand the verb-noun collocation give a speech when encountered in input, but producing it spontaneously is a different matter. This is mainly because in this case the verb give cannot be literally translated from either of the two languages in question, known as LI-L2 incongruence. There is now ample empirical evidence from corpus research that collocations and other types of (semi-) fixed word combinations - termed formulaic sequences (FSs) - are highly frequent in native language use, serving cognitive and social functions (Wray 2002). Hence, it seems logical to assume that L2 learners benefit from knowing FSs in the target language. However, analyses of learner writing have shown that learners at all proficiency levels struggle with the appropriate use of FSs.

Lewis (2000) addresses this issue in his book Teaching Collocation and recommends that ELT practitioners encourage learners to independently notice collocations in language they meet outside the classroom. This, he claims, would increase their collocational competence in English. Even if learners are willing to engage in such activities, there are two problems in Lewis's approach: identifying collocations is difficult for learners and 


\section{Background}

Collocation

Dictogloss

Benefit of a modified dictogloss for collocation learning mere identification is not sufficient for committing collocations to longterm memory (see Boers \& Lindstromberg 2009: I9-2I for discussion). We argue in this study that instructional intervention is necessary to solve these problems and set out to investigate whether the collaborative task dictogloss (Wajnryb i990) can be modified to this end.

The present study uses Henriksen's (2013: 30) definition of collocations as 'frequently recurring two-to-three word syntagmatic units which can include both lexical and grammatical words, e.g. verb + noun (pay tribute), adjective + noun (hot spice), preposition + noun (on guard) and adjective + preposition (immune to)'. This definition is relevant for classroom L2 research as it includes collocations that are both common and meaningful, which is not always the case for frequency-based approaches. The study targets English verb-noun collocations for two reasons: (I) they are central for communication as they are highly frequent and convey the gist of messages, and (2) they are problematic for learners, notably in productive use (Henriksen ibid.: 36). Despite many research attempts at finding effective teaching approaches for collocations and other FSs, there are to date few useful guidelines available for ELT practitioners (see Meunier 2012 for review).

The dictogloss is a collaborative text reconstruction task for L2 grammar instruction (Wajnryb I990). As we will argue below, dictogloss can be modified to improve English learners' knowledge of collocations. The standard dictogloss procedure involves two basic steps ${ }^{\mathrm{I}}$. The teacher first reads a short L2 text aloud several times at normal speed while learners take notes of key words and phrases. Learners then interact in pairs and reconstruct the text in writing based on their notes and what they remember from the reading by the teacher. Dictogloss is thus a type of dictation that crucially does not give learners enough time to copy down the text verbatim. This feature offers opportunities for the co-construction of linguistic knowledge when learners interact, which is argued to facilitate L2 acquisition. For example, Kim (2008) found that the interactive component of dictogloss promoted the learning of single L2 words, as in her study learners who worked in pairs outperformed those who worked individually in post-tests. Furthermore, the dictogloss aligns with three out of four strands ${ }^{2}$ in Nation's (2007) recommendation for a well-balanced language course: meaning-focused input, meaning-focused output, and languagefocused learning. Nation highlights the contribution of these strands to L2 vocabulary growth, particularly language-focused learning where the same forms are given repeated attention (Nation ibid.: 6-7).

The standard dictogloss procedure promotes single word learning as words are repeated intensively when the text is read aloud several times. However, it does not guarantee that collocations will be kept as intact wholes when learners subsequently reconstruct the text, which is a crucial condition for leaving stable memory traces of collocating words in learners' minds. To accomplish this, we argue that teacher intervention through a pre-task activity immediately prior to the dictogloss is necessary. The intention is to reinforce the bond between the two words in the collocations through increased frequency of encounters of intact target 
items in line with usage-based theories of language acquisition (Ellis 2003). The type of pre-task activity that is most effective to this end is an area ripe for investigation. A study by Lindstromberg, Eyckmans and Connabeer (2016) compared the effect of a modified version of the dictogloss to the standard dictogloss in helping their ESP learners remember various FSs. They found that the modified version-where target items were displayed to learners in isolation on a separate paperoutperformed the standard version with no such exposure. We expand on their study by drawing on two theoretical models of L2 input processing in our investigation of the use of dictogloss for collocation learning.

The first model is Barcroft's (2015) Lexical Input Processing theory that favours structural over semantic elaboration of target items for lexical learning. This model is implemented in our study by testing the effect of two types of pre-task activities before the dictogloss proper is performed: one inducing semantic elaboration of target items in the pretask activity, hereafter the SEM dictogloss, and one inducing structural elaboration, hereafter the STRUC dictogloss. In Barcroft's research, semantic elaboration refers to activities where learners work with the meaning of target items, for example, rate their pleasantness. In structural elaboration, learners work with the form of target items, for example, count the letters they contain (see Barcroft ibid.: 85 for details). However, we opted for other equivalent operationalizations of these two types of elaboration; see 'The study' below. The second model is Laufer and Hulstijn's (200I) Involvement Load Hypothesis, which predicts that L2 vocabulary learning depends on the task learners perform when words are processed: tasks with higher involvement load (IL) outperform tasks with lower IL. IL consists of three components: need, search, and evaluation. For a given task, each component receives a score that, when summed, constitutes its IL index: $0-2$ points for need and evaluation, and O-I point for search (the highest IL is thus 5 points). The implementation of SEM dictogloss in our study induces higher involvement than the STRUC dictogloss: 3 vs I point. Both dictoglosses induce moderate need (I point) as it is task-induced and not learner-induced. Search is absent (o points) in both dictoglosses as target items are provided in glossed lists. Evaluation-involving consideration of how a word may be combined with other words-is high (2 points) for SEM dictogloss as it entails writing original sentences and absent (o points) in STRUC dictogloss as the rhyming activity (see 'Participants and materials' below) does not meet any of the requirements for evaluation specified by Laufer and Hulstijn (ibid.: I4-I5).

Aim and research questions
The present study aims to examine which of the two theoretical models for input processing in L2 vocabulary learning, Lexical Input Processing (lex-IP) theory or the Involvement Load Hypothesis (ILH), is a stronger predictor of learning gains for collocations during the performance of a modified dictogloss. The following three research questions (\#I-3) guided the investigation, in which the STRUC dictogloss represents the lex-IP model and the SEM dictogloss the ILH: 
1 Is STRUC dictogloss or SEM dictogloss significantly more effective in inducing learners to produce target items as intact wholes in speech and/or writing during the co-reconstruction phase?

2 Is STRUC dictogloss or SEM dictogloss significantly more effective in promoting learning gains for receptive and/or productive knowledge of target items?

3 If \#2 revealed a significant difference in favour of STRUC dictogloss or SEM dictogloss, does the effectiveness apply to immediate and/or delayed post-tests?

The study

Participants and materials
The first author collected the data for the study in ELT classrooms in a Swedish city. The participants were 64 Li Swedish learners in eighth grade (aged I5) from four secondary schools, I6 learners from each school. The participants signed consent forms and the study (including the unannounced post-tests) had been approved by the Swedish Ethical Review Board. On the basis of the syllabus for English in grade 8 in the Swedish National Curriculum and the CEFR, it was estimated that the learners' English proficiency was at level BI.

The target items were I2 English verb-noun collocations (I-I2): approach a problem, carry a risk, foot the bill, jog one's memory, kick the habit, rivet the attention, attach importance, extend hospitality, pitch a tent, reap benefits, score success, slash costs. Twelve was considered a suitable number of target items for the creation of the two short (II8 words each) dictogloss texts, i.e. six items in each text. The target items were selected based on their status as incongruent $(\mathrm{LI} \neq \mathrm{L} 2)$ verb-noun collocations and their occurrence in two reference works: a collocation dictionary (McIntosh, Francis and Poole 2009), and a bilingual dictionary. We established that our learners did not know the target items beforehand by pre-testing them on 44 other (non-participant) learners. We address the issue of the frequency of our target items under 'Discussion with implications for ELT' below. The target items were integrated into the researcher-developed materials produced in collaboration with two native speakers of English and that made up the two modified dictogloss conditions:

- SEM dictogloss, with pre-task activity I + dictogloss text I (items I-6).

- STRUC dictogloss, with pre-task activity $2+$ dictogloss text 2 (items $7-\mathrm{I} 2)$.

In pre-task activity I, learners received a glossed (translation L2-Li) list of target items I- 6 and were instructed to write original sentences in English including the target items, which they shared orally with their peer. This constitutes the semantic elaboration. In pre-task activity 2, learners received a glossed list of target items 7-I2 and were asked to write down original phrases that rhymed with them, which they shared with their peer, for example 'pay the rent' used by one learner for the target item 'pitch a tent'. This constitutes the structural elaboration. We found these two pre-task activities comparable to the pleasantness rating and letter counting used in Barcroft (2015) in inducing semantic and structural elaboration of target items, respectively, but more educationally relevant based on our experience as ELT practitioners. The two dictogloss texts were of comparable linguistic difficulty as determined by an analysis of the frequency of their vocabulary using the Vocab Profile at www.lextutor.ca. 
To assess learning we constructed two post-tests that measured productive and receptive knowledge of target items. In the productive test, learners translated target items from Swedish into English using the following format: friska upp minnet_J__ one's memory. In this example, learners needed to write the two letters 'og' to complete the target item in question. The first letter of the verb was supplied to avoid possible but undesirable answers. For the test of receptive knowledge, learners selected one of four options in Swedish corresponding with the target item in English as exemplified below:

Jog one's memory
a friska upp minnet
b förlora minnet
c försvaga minnet
d träna upp minnet

It follows that learning collocations in this study emphasizes controlled productive/receptive knowledge in an elicitation test format and not in free written or spoken production. Investigating the latter type of knowledge requires another research design and it was not our intention to do that.

We used a within-subjects design, whereby all learners complete all conditions; therefore in our study all learners did both STRUC and SEM dictogloss. In the alternative design option, a between-subjects design, all learners only complete one condition (i.e. if we had let our learners only do either STRUC or SEM dictogloss). The strength of the within-subjects design is that it investigates the effect of the condition, whereas in the between-subjects design there is a risk that extraneous variables, such as learner proficiency, influence the results. This is because it may well be that a majority of high proficiency learners complete just one given condition and their proficiency — rather than the condition itself - explains their (high) post-test scores. This risk is eliminated in a within-subjects design.

The learners were already familiar with the dictogloss procedure. They worked in self-selected pairs $(n=32)$ and were audio-recorded while co-reconstructing the texts. After the two modified dictoglosses had been completed, learners handed in all materials and immediate unannounced post-tests were administered. Learners first took the test of productive knowledge, handed it in and then took the test of receptive knowledge. This order was intended to control for any 'practice effect' that may have been induced by first taking the easier test of receptive knowledge. The fact that the order of the two modified dictoglosses was reversed for half of the learners-known as 'counterbalanced'-allowed us to control for any recency effects that may occur for immediate post-tests, i.e. that learners remember target items in the second/most recently performed modified dictogloss better than the first one. Three weeks later, unannounced delayed post-tests were administered similarly to the immediate post-tests. It follows that the learning conditions did not induce learners to learn the target items intentionally (cf. Laufer and Hulstijn 200I: IO-II).

Each data collection session took place in a large classroom during regular classes with four pairs of learners-each pair sitting in one of the 


\section{Data analysis}

Data collection

\section{Results}

TABLE 1

Comparisons of learner output for the two modified versions of dictogloss: individual (1-4) and in pairs $(5-6)$ corners-while the other non-participant students were given another task to perform outside class. The seating arrangement enabled us to control the experiment tightly for task performance, acoustic conditions for audiorecording and post-test supervision.

The data collected consist of the learners' post-test scores, their audiorecorded collaborative dialogues, and co-reconstructed written versions of the two dictogloss texts. The post-tests were marked dichotomously with I point for a correct answer and o points for an incorrect answer. Unlike the test of receptive knowledge in which learners circled an option 'a-d', the test of productive knowledge required scoring criteria. Incorrectly spelled answers received I point if they were found to be acceptable phonetic equivalents of the target verb or contained an inflected form. For example, footing the bill for the target item foot the bill was given I point, while fit the bill was not. A second trained rater scored ro per cent of the post-tests and the interrater reliability reached .98. We listened to the collaborative dialogues and tallied the target items that were said out loud as intact wholes by at least one of the pair members. We also counted the target items that learners had written out as intact wholes in their co-written texts.

Table I presents the statistics for the two modified versions of the dictogloss: SEM and STRUC. As shown in the table, the SEM dictogloss condition generated higher learning outcomes than the STRUC dictogloss condition on all post-tests for the individual learner output (see \#I-4). Furthermore, learners in the SEM dictogloss condition spoke and wrote more target items as intact wholes in their pairs compared to the STRUC dictogloss condition (see \#5-6). Statistical analyses ${ }^{3}$ were run, revealing significant differences in outcomes for the six comparisons, which means there is statistical evidence that the differences were not due to chance. Effect sizes $(d)$ were also calculated on these differences, where .4 represents a small effect, .7 a medium effect, and I a large effect. The effect size is a staple in leading language learning journals as it indicates whether the difference between groups is important or negligible.

\begin{tabular}{|c|c|c|c|c|}
\hline Learner output & $\begin{array}{l}\text { Modified } \\
\text { dictogloss }\end{array}$ & $\begin{array}{l}M \text { (max: } 6 \\
\text { points) }\end{array}$ & $S D$ & $t$ \\
\hline \multirow[t]{2}{*}{ 1. Post-test productive } & SEM & 4.06 & 1.70 & $5.78 * * *$ \\
\hline & STRUC & 2.75 & 1.81 & $d=.72$ \\
\hline \multirow[t]{2}{*}{ 2. Post-test receptive } & SEM & 5.81 & .47 & $5.06 * * * *$ \\
\hline & STRUC & 5.22 & .97 & $d=.70$ \\
\hline \multirow[t]{2}{*}{ 3. Delayed post-test productive } & SEM & 3.59 & 1.59 & $7.62 * * *$ \\
\hline & STRUC & 2.19 & 1.68 & $d=.86$ \\
\hline \multirow[t]{2}{*}{ 4. Delayed post-test receptive } & SEM & 5.81 & .47 & $4.24 * \cdots * *$ \\
\hline & STRUC & 5.47 & .84 & $d=.50$ \\
\hline \multirow[t]{2}{*}{ 5. Spoken target items } & SEM & 3.88 & 1.70 & $4.49 * * * *$ \\
\hline & STRUC & 2.88 & 1.65 & $d=.56$ \\
\hline \multirow[t]{2}{*}{ 6. Written target items } & SEM & 3.75 & 1.71 & $5.15 * * * *$ \\
\hline & STRUC & 2.69 & 1.58 & $d=.64$ \\
\hline
\end{tabular}

Notes: $n=64, M=$ mean score, $S D=$ standard deviation, $d=$ effect size, $* * * *=p<001$. 


\section{Discussion with implications for ELT}

This study set out to provide ELT practitioners with a strategy for boosting learners' collocation knowledge, a key component of advanced or nativelike proficiency for which few useful instructional guidelines are available. We compared the effects of having learners engage with target items in two different ways prior to performing a dictogloss and collected production data (whether learners verbalized intact target items) and test data (learners' post-test scores). Results show that, contrary to the predictions of Lexical Input Processing theory (Barcroft 20I5), structural elaboration of target items was significantly less effective than semantic elaboration for all six comparisons: for the verbalization of target items as intact wholes in speech and writing, on productive and receptive target item knowledge, and on immediate and delayed post-tests.

The findings of the study lend empirical support to the Involvement Load Hypothesis (ILH; Laufer and Hulstijn 200I). In our study, SEM dictogloss theoretically generated higher involvement than STRUC dictogloss and may therefore have been more effective in making learners reproduce target items as intact wholes, which led to increased chances of learning as demonstrated in the post-tests. A recent study by Zou (2OI7) expanded on the ILH by comparing the effects of composition-writing with sentencewriting on word learning and found a superior effect for the former. This result resonates with our study. ELT practitioners may consider using composition-writing in place of sentence-writing before doing the SEM dictogloss, leading to even deeper processing of target items and increased likelihood of learning. However, composition-writing is clearly more challenging than sentence-writing and is therefore more suitable for learners at the intermediate proficiency level and beyond. For lower proficiency learners, we suggest other pre-task activities with semantic elaboration of target items such as finding synonyms and antonyms in both their LI and the L2.

Recognizing what is a collocation requires technical knowledge and ELT practitioners may therefore not be convinced of the practicality in using the SEM dictogloss to boost learners' collocation knowledge. There is no shortage of online resources that may assist teachers in selecting appropriate texts for learners, for example with regard to how frequent and thus useful the words are. Regrettably, these resources focus on single words and the ones that target FSs are currently cumbersome for non-specialists. We therefore recommend that teachers equip themselves with an updated collocation dictionary offered by most publishing houses. Teachers should target collocations that pose problems for their learners, based on incongruence as in our study, and also collocations that may be used in a wide range of contexts. As an example, we present the selection process step-by-step below, followed by Figure I containing an authentic text. The text contains eleven verb-noun combinations out of which eight are listed in a collocation dictionary (McIntosh, Francis and Poole 2009): apply for a license, apply for a permit, save time, complete a form, have a permit, have practice, take a course, take a test.

To prepare a SEM dictogloss:

1 Decide on a topic appropriate for your learners.

2 Find a short text (< I50 words) on that topic. 
FIGURE 1

Screenshot of the web page 'Get a driver license' (accessed on 25 September 2014)

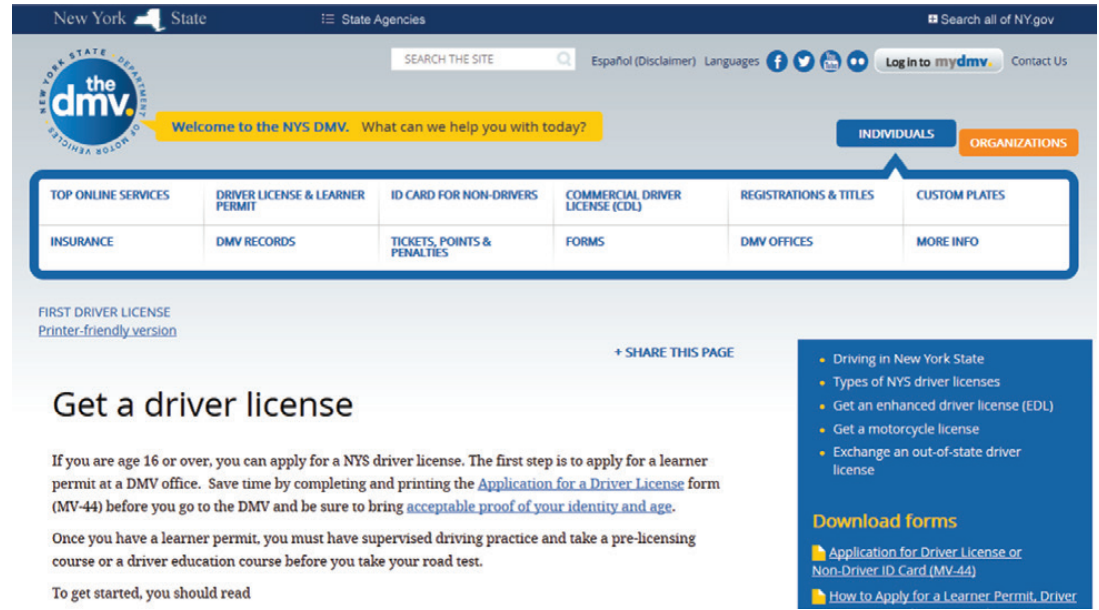

3 Read the text and highlight all verb-noun combinations.

4 Identify the collocations by looking up the noun component in a collocation dictionary.

5 Select a suitable semantic elaboration pre-task activity depending on learner proficiency.

This study targeted incongruent verb-noun collocations but there is no reason that the findings would not apply to other types of collocations and FSs, the most relevant for ELT being adjective-noun (e.g. a tall building) and adverb-adjective (e.g. strikingly beautiful) collocations, as well as idioms (e.g. call the shots) and phrasal verbs (e.g. call off). These four types are mentioned as they are frequent in all types of English texts and easily lend themselves to being implemented in the SEM dictogloss. The two types of collocations are found in the cited collocation dictionary, while idioms and phrasal verbs require specific dictionaries that are commercially available.

The use of corpus tools for L2 collocation learning is recommended by several researchers (e.g. Meunier 20I2; Timmis 20I5). We recognize the potential educational value of analysing collocations in concordancers, a corpus-based program that presents co-occurring words of search terms in separate lines on the computer screen. However, we are not yet convinced of their usefulness for learning L2 FSs for two reasons. First, corpus tools are resource-demanding: they are costly and require specific in-service training in their use and with regard to which FSs merit classroom time. Second, while commendably thorough and explicit about corpus approaches to collocation learning for ELT, Timmis (20I5) does not specifically address how target items may be committed to learners' memory. We argue that our study, in the practicality and effectiveness of the SEM dictogloss, is a step towards addressing both these issues.

Two limitations of the study should be discussed. The first one is the lack of control of frequency for the i2 target items. As mentioned above, we followed strict criteria for the selection of target items, but it may be that the individual words in the target items were more or less learnable, which may have impacted the outcome of the study. For example, the frequent verb 


\section{Conclusion}

carry (in carry a risk) is likely to be known to participants, whereas the less frequent rivet (in rivet the attention) is unlikely to be known. However, the novelty effect, highlighting the learnability of new material, runs counter to this assumption: because carry was already known it may have been less noticeable - and less learnable in its collocation context - than the unknown rivet (see Henriksen 2013: 33 for discussion). Furthermore, the frequency of our target items as wholes also varies. The second limitation is that pragmatic and syntactic knowledge of target items was not tapped in the post-test formats. This implies that we do not know whether the learners are able to use the target items appropriately and correctly, for example the genres in which they are typically used and the prepositional phrases with which the target items are constructed, for example carry a risk of doing something. However, tapping into these aspects of depth of collocation knowledge requires a different testing format, for example asking learners to provide metalinguistic descriptions. We did not include such measures because of the additional cognitive strain associated with them.

The dictogloss is a practical classroom task with theoretical advantages for L2 learning in general. As shown in the current study, the SEM dictogloss also offers great potential for ELT practitioners wanting to improve learners' knowledge of collocations. The main advantage of using the SEM dictogloss over the STRUC dictogloss is the medium effect size it produced for productive knowledge of incongruent target collocations in the delayed post-test. This result is evidence of durable learning gains, which should be the priority for any pedagogical activity. We call for more L2 classroom-based research that further expands the possibilities for dictogloss to increase learners' competence in using FSs. This may involve examining how the analysis and correction stage of the original dictogloss procedure (see Wajnryb I990: 9) may be fruitfully used to this end or comparing the effects of different group constellations in terms of sizes and proficiency levels.

Final version received March 2018

Notes

1 Wajnryb’s (I990) original dictogloss procedure includes four steps: preparation, dictation, reconstruction, and analysis and correction, and may involve learners working in small groups.

2 Nation's (2007) fourth strand, fluency development, is not covered by the dictogloss.

3 Paired samples $t$-tests were run on the difference between the means in the six comparisons using SPSS 24.

\section{References}

Barcroft, J. 20I5. Lexical Input Processing and Vocabulary Learning. Amsterdam: John Benjamins.

Boers, F. and S. Lindstromberg. 2009. Optimizing a Lexical Approach to Instructed Second Language Acquisition. Basingstoke: Palgrave Macmillan.
Ellis, N. C. 2003. 'Constructions, chunking and connectionism: the emergence of second language structure' in C.J. Doughty and M.H. Long (eds.). Handbook of Second Language Acquisition, 63-103. Oxford: Blackwell.

Henriksen, B. 20I3. 'Research on L2 learners' collocational competence and development - a progress report' in C. Bardel, C. Lindqvist, and B. Laufer (eds.). Vocabulary Acquisition, Knowledge and Use. New Perspectives on Assessment and Corpus Analysis, 29-56. Eurosla Monograph Series 2.

Kim, Y. 2008. 'The contribution of collaborative and individual tasks to the acquisition of L2 vocabulary'. The Modern Language Journal 92: II4-I30.

Laufer, B. and J.H. Hulstijn. 200I. 'Incidental vocabulary acquisition in a second language. The construct of task-induced involvement'. Applied Linguistics 22: I-26. 
Lewis, M. (ed.). 2000. Teaching Collocation. Further Developments in the Lexical Approach. Hove: Language Teaching Publications.

Lindstromberg, S., J. Eyckmans, and R. Connabeer. 20I6. 'A modified dictogloss for helping learners remember L2 academic English formulaic sequences for use in later writing'. English for Specific Purposes 4I: I2-2I.

Mclntosh, C., B. Francis, and R. Poole. 2009. Oxford Collocations Dictionary for Students of English. Oxford: Oxford University Press.

Meunier, F. 2012. 'Formulaic language and language teaching'. Annual Review of Applied Linguistics 32:

III-29.

Nation, I. S. P. 2007. 'The four strands'. Innovation in Language Learning and Teaching I/I: I-I2.

Timmis, I. 2015. Corpus Linguistics for ELT: Research and Practice. New York: Routledge.

Wajnryb, R. I990. Grammar Dictation. Oxford: Oxford University Press.

Wray, A. 2002. Formulaic Language and the Lexicon. Cambridge: Cambridge University Press.
Zou, D. 20I7. 'Vocabulary acquisition through cloze exercises, sentence-writing and composition-writing: extending the evaluation component of the involvement load hypothesis'. Language Teaching Research 2I/I: 54-75.

\section{The authors}

Per Snoder taught English, French and Italian in high schools in Sweden for ten years. He also worked as a lecturer in Language Education at Stockholm University for four years. He is now a PhD student with a keen interest in formulaic language and language pedagogy.

Email: per.snoder@isd.su.se

Barry Lee Reynolds taught ESL, EFL, EAP, and ESP in higher education in Taiwan and the USA for I3 years. Since moving to Macau in 2016 he balances time between pre-service English teacher training and research in vocabulary acquisition, L2 literacy, learning strategies, and other areas of applied linguistics in ELT. Email: barryreynolds@umac.mo 